\title{
Antibacterial and Antibiofilm Activities of Nonpolar Extracts of Allium stipitatum Regel. against Multidrug Resistant Bacteria
}

\author{
Arunkumar Karunanidhi, ${ }^{1,2}$ Ehsanollah Ghaznavi-Rad $\left(\mathbb{D},{ }^{3}\right.$ Rukman Awang Hamat $\left(\mathbb{D},{ }^{1}\right.$ \\ Mallikarjuna Rao Pichika, ${ }^{4}$ Leslie Than Thian Lung, ${ }^{1}$ Fazlin Mohd Fauzi, ${ }^{2}$ \\ Sridevi Chigurupati $\mathbb{D}^{5},{ }^{5}$ Alex van Belkum, ${ }^{6}$ and Vasanthakumari Neela $\mathbb{i}^{1}$ \\ ${ }^{1}$ Department of Medical Microbiology and Parasitology, Faculty of Medicine and Health Sciences, Universiti Putra Malaysia, \\ 43400 Serdang, Selangor Darul Ehsan, Malaysia \\ ${ }^{2}$ Department of Pharmacology and Chemistry, Faculty of Pharmacy, Universiti Teknologi MARA, \\ 42300 Bandar Puncak Alam, Selangor Darul Ehsan, Malaysia \\ ${ }^{3}$ Department of Microbiology and Immunology, Faculty of Medicine, Arak University of Medical Sciences, Basij Square, \\ Arak 38481-7-6941, Iran \\ ${ }^{4}$ Department of Pharmaceutical Chemistry, School of Pharmacy, International Medical University, No. 126, \\ Jalan Jalil Perkasa 19, Bukit Jalil, 57000 Kuala Lumpur, Malaysia \\ ${ }^{5}$ Department of Medicinal Chemistry and Pharmacognosy, College of Pharmacy, Qassim University, Buraidah 51452, Saudi Arabia \\ ${ }^{6}$ La Balme Microbiology Unit, BioMerieux, 3 route de Port Michaud, 38390 La Balme-les-Grottes, France
}

Correspondence should be addressed to Vasanthakumari Neela; neela2000@hotmail.com

Received 23 February 2018; Revised 8 May 2018; Accepted 25 June 2018; Published 11 July 2018

Academic Editor: Paul M. Tulkens

Copyright (c) 2018 Arunkumar Karunanidhi et al. This is an open access article distributed under the Creative Commons Attribution License, which permits unrestricted use, distribution, and reproduction in any medium, provided the original work is properly cited.

The present study assessed the in vitro antibacterial and antibiofilm potential of hexane (ASHE) and dichloromethane (ASDE) extracts of Allium stipitatum (Persian shallot) against planktonic cells and biofilm structures of clinically significant antibiotic resistant pathogens, with a special emphasis on methicillin-sensitive Staphylococcus aureus (MSSA), methicillin-resistant S. aureus (MRSA), and emerging pathogens, Acinetobacter baumannii and Stenotrophomonas maltophilia. Antibacterial activities were determined through disk diffusion, minimum inhibitory concentration (MIC), minimum bactericidal concentration (MBC), timekill kinetics, and electron microscopy. Antibiofilm activity was assessed by XTT [2,3-bis(2-methoxy-4-nitro-5-sulfo-phenyl)-2Htetrazolium-5-carboxanilide] reduction assay and by confocal laser scanning microscopy (CLSM). The zone of inhibition ranged from 13 to $33 \mathrm{~mm}$, while the MICs and MBCs ranged from 16 to $1024 \mu \mathrm{g} \mathrm{mL} \mathrm{m}^{-1}$. Both ASHE and ASDE completely eradicated overnight cultures of the test microorganisms, including antibiotic resistant strains. Time-kill studies showed that the extracts were strongly bactericidal against planktonic cultures of S. aureus, MRSA, Acinetobacter baumannii, and S. maltophilia as early as 4 hours postinoculation (hpi). ASHE and ASDE were shown to inhibit preformed biofilms of the four biofilm phenotypes tested. Our results demonstrate the potential therapeutic application of ASHE and ASDE to inhibit the growth of gram-positive and gram-negative biofilms of clinical significance and warrant further investigation of the potential of A. stipitatum bulbs against biofilm-related drug resistance.

\section{Introduction}

Biofilms are ubiquitous in nature which can be found at the bottom of streams to extremely hot waters of hot springs. In human health, biofilms pose a great threat due to their resistant nature to antibiotics, contamination of indwelling medical devices, forming dental plaques causing tooth decay, chronicity in wounds, and association with several illnesses from cystic fibrosis to otitis media. Biofilm forms of microbes are up to 1000 -fold more resistant to antibiotics than their planktonic counterparts $[1,2]$.

Infectious diseases caused by multidrug resistant (MDR) pathogens are the biggest challenge in healthcare. The conditions are made more worrisome by the biofilm associated 
infections. Such diseases are most frequently caused by $S$. aureus, S. epidermidis, Pseudomonas aeruginosa, A. baumannii, and Enterobacteria such as Escherichia coli [3-5].

Few novel antibacterial agents have been developed in recent years and their bacteriostatic or bactericidal activity results in selective pressure, with antimicrobial resistance as an unavoidable aftermath of their use [6]. In addition, effective therapies which target bacterial biofilms are scarce due to their implicit resistance to antibiotics [7]. An extensive review by $\mathrm{Wu}$ et al. [8] has shared the clinical experiences/challenges in managing biofilm infections. If the infections are not involving foreign body, a high dose of antibiotics or combinational therapy may sometimes eliminate the infections. But in cases where foreign bodies such as catheters, shunts, heart valves, pacemakers, stents, breast implants, intrauterine devices, contact lenses, etc. are used, the removal of material, followed by treatment is often necessary.

To date, several agents from natural products to synthetic compounds have been routinely used or evaluated for treating biofilm infections [9-13]; however, the integrity of the cells in the biofilm matrix and reduced permeability to antibiotics limit the complete detachment or destruction of biofilms. Hence, the search for new antimicrobials and biofilm dissolving agents is always vital in the human medicine.

Allium stipitatum that belongs to the Amaryllidaceae family is a wild edible plant mostly found in the cold mountains of central, south, and western Iran as well as some provinces of Turkey and central Asia $[14,15]$. Persian shallot is locally known as "Mooser" in Iran and widely used as a spice and flavoring agent in Persian foods, especially as added ingredients to yogurt, salads, and pickling mixtures. The appearance, shape, color, weight, texture, and storage tissues differentiate A. stipitatum from the common shallot, A. ascalonicum $[15,16]$. Unlike other Allium members, Persian shallot usually consists of a single bulb and rarely two bulbs [15]. Dried bulbs of A. stipitatum are frequently used in Persian folklore medicine for various ailments, like anti-inflammatory disorders, diarrhoea, gout, haemorrhoids, psoriasis, rheumatic arthritis, stomach pain, etc. [17]. Several studies performed on A. stipitatum elucidated its antibacterial, antiproliferative, anthelmintic, antiprotozoal, immunomodulatory, and wound healing properties [18-23]. Moreover, in our recent study, we have shown that $A$. stipitatum exerts anti-MRSA and wound healing activity in a mouse model of burn wound and infection [24]. We have also reported that both the extracts were relatively noncytotoxic towards mammalian cells and effective in eradicating MRSA colonized in thermal wounds. However, the effect of $A$. stipitatum on bacterial biofilm formation is still not clearly defined, requiring further investigation. In this study, we investigated the effects of ASHE and ASDE against a panel of medically important gram-positive and gram-negative bacteria followed by SEM and TEM examination of the in vitro effects of ASHE and ASDE on bacterial cells at different concentrations. We further provide evidence that ASHE and ASDE can increase the susceptibility of bacterial biofilms with emphasis on MSSA, MRSA, A. baumannii, and S. maltophilia biofilms.

\section{Materials and Methods}

2.1. Bacterial Strains and Culture Conditions. Test microorganisms Acinetobacter baumannii ATCC 19606, Acinetobacter lwoffi, Enterobacter spp., Escherichia coli ATCC 25922, Klebsiella pneumoniae, methicillin-resistant Staphylococcus aureus (MRSA) ATCC 43300, Staphylococcus aureus ATCC 25923, Pseudomonas aeruginosa ATCC 27853, Salmonella typhi, Shigella dysenteriae, Stenotrophomonas maltophilia ATCC 13637, and vancomycin resistant enterococci (VRE) were obtained from the Medical Microbiology and Parasitology Laboratory at Universiti Putra Malaysia (UPM). All strains were confirmed by cultural and biochemical characteristics and maintained in glycerol stock cultures at $-80^{\circ} \mathrm{C}$ prior to use. Bacterial cultures were propagated by streaking onto tryptic soy agar (TSA) or nutrient agar (NA). Single colonies of bacteria from the overnight cultures were inoculated into Luria-Bertani (LB) broth or brain heart infusion broth $(\mathrm{BHI})$ and incubated in a shaking incubator at $37^{\circ} \mathrm{C}$.

2.2. Chemicals. Merck supplied dimethyl sulfoxide (DMSO) and bacterial growth media [brain heart infusion (BHI) broth, Mueller-Hinton agar (MHA), tryptic soy broth (TSB), Mueller-Hinton broth (MHB), and Luria-Bertani (LB) broth]. Resazurin (7-hydroxy-3H-phenoxazin-3-one 10oxide, monosodium salt) and phosphate-buffered saline (PBS) were purchased from Fisher Scientific (M) Sdn Bhd, Malaysia. Antibiotic discs and powder were purchased from Oxoid Limited, Hampshire, UK. Filter paper discs $(6 \mathrm{~mm}$ diameter) were purchased from GE Healthcare, Malaysia; sterile swabs with wooden handle (FisherbrandTM) were purchased from Thermo Fisher Scientific Sdn. Bhd, Malaysia; and 96-well polystyrene microtitre plates (CTPP, Trasadingen, Switzerland) were obtained from NeoScience Sdn. Bhd, Malaysia. Resazurin was prepared as a stock solution of $100 \mu \mathrm{g} \mathrm{mL}^{-1}$ and was used at a final concentration of $0.01 \%(\mathrm{w} / \mathrm{v})$ in PBS ( $\mathrm{pH} 7.2)$. The stock solution was filter sterilized in a $0.20 \mu \mathrm{m}$ pore filter and stored in dark at $4^{\circ} \mathrm{C}$. XTT [2,3-bis(2-methoxy-4-nitro-5-sulfo-phenyl)-2Htetrazolium-5-carboxanilide] was obtained as XTT sodium salt (Sigma Aldrich, MO, USA). Stock solution of XTT (1 $\mathrm{mg} \mathrm{mL}^{-1}$ in PBS) was prepared and was used at a final concentration of $0.01 \%(\mathrm{w} / \mathrm{v})$ in distilled water. The stock solution was filter sterilized in a $0.20 \mu \mathrm{m}$ pore filter and stored at $-20^{\circ} \mathrm{C}$ in dark.

2.3. Disk Diffusion Assay and Determination of MICs and MBCs. The antibacterial activities of ASHE and ASDE were assessed by disk diffusion method as previously described [25]. For disk diffusion assay, ASHE and ASDE were prepared freshly at a concentration of $10 \mathrm{mg} \mathrm{mL}^{-1}$ in $10 \%$ DMSO. Sterile antibiotic assay filter paper discs of $6 \mathrm{~mm}$ diameter were placed on MHA plates and $20 \mu \mathrm{L}\left(10 \mathrm{mg} \mathrm{mL}^{-1}\right.$ corresponding to $200 \mu \mathrm{g}$ extract) of ASHE or ASDE was loaded onto the filter paper discs. Appropriate antibiotics were included as positive controls, while filter paper disc loaded with $20 \mu \mathrm{L}$ of DMSO (10\%) was included as a negative control (diluent control). 
The plates were incubated at $37^{\circ} \mathrm{C}$ and the inhibition zones were measured after $24 \mathrm{~h}$ incubation. The MICs and MBCs of ASHE and ASDE were determined by broth microdilution method and spread plate technique, respectively, by following the previously described methods $[24,26]$.

2.4. Time-Kill Assay. Time-kill assay was carried out on selected bacterial strains (MSSA, MRSA, A. baumannii, and S. maltophilia) according to the method described previously with minor modifications [26]. Bacterial suspensions were diluted to $1 \times 10^{6} \mathrm{CFU} \mathrm{mL}^{-1}$. ASHE and ASDE concentrations were adjusted to $1 \mathrm{x}, 2 \mathrm{x}$, and $4 \mathrm{x}$ MICs. Bacterial cultures treated with varying concentrations of the extracts were incubated at $37^{\circ} \mathrm{C}$ for $0,0.5,1,2,4,8,12$, and $24 \mathrm{~h}$. Aliquots of $100 \mu \mathrm{L}$ were pipetted out from each tube at each time point, serially diluted in PBS, and spread-plated onto MHA plates. Tubes without ASHE and ASDE served as growth controls (0x). The plates were incubated at $37^{\circ} \mathrm{C}$ for $24 \mathrm{~h}$ followed by the enumeration of bacterial colonies. Killing curves were constructed by plotting the $\log _{10} \mathrm{CFU} \mathrm{mL} \mathrm{m}^{-1}$ versus time over a $24 \mathrm{~h}$ time period. Bactericidal activity (99.9\% kill) was defined as $\mathrm{a} \geq 3-\log _{10} \mathrm{CFU} \mathrm{mL}^{-1}$ reduction in colony count from the initial inoculum.

2.5. Ultrastructure Microscopical Analysis. The ultrastructural changes in the bacteria treated with ASHE/ASDE were examined by SEM and TEM. Bacterial samples for electron microscopy were prepared by following the previously described method [27] with minor modifications. Cultures of $S$. aureus, MRSA, A. baumannii, and S. maltophilia were grown in TSB or BHI broth for $24 \mathrm{~h}$ at $37^{\circ} \mathrm{C}$. The cultures were diluted to a final concentration of $5 \times 10^{7} \mathrm{CFU} \mathrm{mL} \mathrm{m}^{-1}$ in broth (1:10) and aliquots of $5 \mathrm{~mL}$ were placed into each well of a 6-well polystyrene tissue culture plate. Samples were treated with varying concentrations of ASHE and ASDE (1x, $2 \mathrm{x}$, and $4 \mathrm{x}$ MICs) for $4 \mathrm{~h}$ (based on the results obtained in time-kill studies) and cells were harvested by centrifugation and washed twice with $0.1 \mathrm{M}$ PBS ( $\mathrm{pH}$ 7.2) before proceeding for SEM and TEM analysis.

2.5.1. Scanning Electron Microscopy (SEM). Bacterial cells were fixed with buffered glutaraldehyde (4\%) for 12-24 h, washed thrice with $0.1 \mathrm{M}$ sodium cacodylate buffer, and postfixed in $0.1 \mathrm{M}$ osmium tetroxide $\left(\mathrm{OsO}_{4}\right)$ for $2 \mathrm{~h}$ at $4^{\circ} \mathrm{C}$. Following fixation, samples were dehydrated in a graded acetone series (35-100\%), mounted using double-sided tape, and subjected to critical point drying (CPD 030, Bal-TEC, Switzerland) and gold coating in a sputter coating unit (E5100 Polaron, UK). The specimens were examined in a SEM (JEOL JSM-6400, Japan) at $15 \mathrm{kV}$.

2.5.2. Transmission Electron Microscopy (TEM). Bacterial cells were fixed with glutaraldehyde and postfixed similar to the sample preparation as described for SEM in Section 2.5.1. Samples were dehydrated with a series of acetone grade (35\%, 50\%, 75\%, 95\%, and 100\%) for $10-15 \mathrm{~min}$ each and infiltrated with increasing concentrations of acetone:resin mixture. Epoxy resin embedded samples were subjected to ultramicrotome and the ultrathin sections were doublestained with uranyl acetate and lead citrate. The specimens were examined under a Hitachi H-7100 TEM (Hitachi, Ibaragi) at $120 \mathrm{kV}$.

\subsection{Antibiofilm Effect of ASHE and ASDE}

2.6.1. Antibiofilm Assay. Biofilms of S. aureus, MRSA, A. baumannii, and $S$. maltophilia were produced by microtitre plate method [28]. Briefly, overnight broth cultures of the bacterial samples were grown in $\mathrm{BHI}$ broth to a turbidity

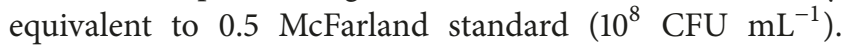
Each biofilm phenotype was added to 24 wells of a sterile microtitre plate and incubated at $37^{\circ} \mathrm{C}$ for $6 \mathrm{~h}$ under static conditions. After $6 \mathrm{~h}$ of adhesion, nonadherent cells were removed from each well and the wells were rinsed with $100 \mu \mathrm{L}$ of physiological saline, and subsequently $100 \mu \mathrm{L}$ of fresh medium was added to each well and incubated for $24 \mathrm{~h}$. After $24 \mathrm{~h}$ of adhesion and biofilm formation, the supernatant was again removed and the wells were rinsed with physiological saline and $100 \mu \mathrm{L}$ of ASHE and ASDE at concentrations of $1 \mathrm{x}, 2 \mathrm{x}$, and $4 \mathrm{x}$ MICs were added. Wells without antibiotics or extracts were considered "untreated". Untreated cells/negative controls were incubated with $100 \mu \mathrm{L}$ of DMSO (5\%) for an additional $12 \mathrm{~h}$ at $37^{\circ} \mathrm{C}$ with gentle shaking and the viability of biofilms was quantified by XTTcalorimetric assay.

2.6.2. XTT Reduction Assay. The antibiofilm potential of ASHE and ASDE to inactivate biofilms was assessed by microtitre plate assay [29]. Before each assay, fresh XTT solutions were prepared by dissolving $4 \mathrm{mg}$ of XTT (Sigma) in $10 \mathrm{~mL}$ prewarmed $\left(37^{\circ} \mathrm{C}\right) \mathrm{PBS}$. This solution was supplemented with $100 \mu \mathrm{L}$ menadione stock solution, containing $55 \mathrm{mg}$ menadione (Sigma) in $100 \mathrm{~mL}$ acetone. The effect of ASHE and ASDE was tested at concentrations of $0 \mathrm{x}$ (untreated/negative control), $1 \mathrm{x}, 2 \mathrm{x}$, and $4 \mathrm{x}$ MICs against $24 \mathrm{~h}$ old biofilms formed earlier. Posttreated biofilm plates were washed thrice with $200 \mu \mathrm{L}$ of sterile PBS. The wells were dried and $100 \mu \mathrm{L}$ of XTT-menadione solution was added to each well and incubated at $37^{\circ} \mathrm{C}$ in dark for $5 \mathrm{~h}$. The contents of the wells were pipetted into fresh $1.5 \mathrm{~mL}$ Eppendorf tubes and centrifuged at $15,000 \mathrm{~g}$ for $4 \mathrm{~min}$. One hundred microlitres of the clear supernatant from each well was transferred to a sterile 96-well flat-bottomed microtitre plate and the absorbance of the adherent biofilm was read at $490 \mathrm{~nm}$ in a microplate reader (BioTek EL808, USA).

2.7. In Situ Visualization of the Antibiofilm Effects of ASHE and ASDE by Confocal Laser Scanning Microscopy (CLSM). In situ antibiofilm potential of ASHE and ASDE on preformed biofilms of S. aureus, MRSA, A. baumannii, and S. maltophilia was visualized under a CLSM (Olympus FV1000-IX81). Biofilms were carefully washed with PBS and stained with LIVE/DEAD ${ }^{\circledR}$ BacLight Bacterial Viability Kit (Invitrogen, Grand Island, NY, USA). Equal volumes of live stain (green fluorescence) and dead stain (red fluorescence) were mixed and diluted to a working solution of $0.3 \%$ in sterile distilled 
water. The staining procedure was carried out according to the method described previously [30]. CLSM images were captured and processed using a Fluoview ${ }^{\circledR}$ FV1000 live cell imaging software.

2.8. Statistical Analysis. All assays were performed in triplicate (at a minimum) and repeated three times. Statistical analyses were performed using GraphPad Prism 6.0 software (GraphPad, San Diego, CA, USA) by one-way analysis of variance (ANOVA) with Dunnett's multiple comparison test. Values are expressed as $\pm \mathrm{SD}$. ${ }^{* * *} p<0.001$ compared with the control.

\section{Results}

3.1. Antibacterial Activities of ASHE and ASDE. Both ASHE and ASDE showed promising antibacterial activity against all the bacteria tested and the inhibition zones ranged from 13 to $33 \mathrm{~mm}$ for ASHE and 15 to $32 \mathrm{~mm}$ for ASDE at $10 \mathrm{mg} \mathrm{mL}^{-1}$ concentration (Table 1). Both gram-positive and gram-negative organisms were susceptible to ASHE and ASDE. Of the 12 organisms tested, MDR pathogens, namely, A. baumannii, MRSA, and S. maltophilia, were highly susceptible to ASHE and ASDE with zone sizes ranging from 23 to $28 \mathrm{~mm}$. The antibacterial results of MRSA were represented in this manuscript in order to facilitate better understanding for the readers. Meanwhile the diameter zone of inhibition for VRE and P. aeruginosa ranged from 13 to 15 $\mathrm{mm}$ (Figure 1). The largest zone of inhibition was observed in A. lwoffii exerted by ASHE $(33 \mathrm{~mm})$ at a concentration of $200 \mu \mathrm{g} / \mathrm{disc}$. The MICs of ASHE and ASDE ranged from 16 to $1024 \mu \mathrm{g} \mathrm{mL}^{-1}$, while the MBCs ranged between 32 and 4096 $\mu \mathrm{g} \mathrm{mL}^{-1}$ (Table 1). MSSA, MRSA, and A. lwoffii were found to be highly susceptible, especially at very low concentrations.

3.2. Analysis of Bacterial Killing Kinetics. Studies on the bacterial killing kinetics of ASHE and ASDE on MSSA, MRSA, A. baumannii, and S. maltophilia showed that the growth controls in MHB without any antibiotics (untreated) maintained their viability for $24 \mathrm{~h}$. However, MSSA, MRSA, A. baumannii, and S. maltophilia treated with ASHE and ASDE at $1 x, 2 x$, and $4 x$ MICs showed a significant reduction in growth, indicating that both extracts were strongly bactericidal by killing $>90 \%$ of the cells. Bactericidal endpoints were achieved at $2 \mathrm{~h}$ for MRSA (Figures 2(b) and 3(b)) and $4 \mathrm{~h}$ for MSSA (Figures 2(a) and 3(a)), A. baumannii (Figures 2(c) and $3(\mathrm{c})$ ), and $S$. maltophilia (Figures $2(\mathrm{~d})$ and $3(\mathrm{~d})$ ). At $1 \times$ and $4 \times$ MICs, the average reduction in CFUs was found to be $\sim 1.9$ and $\sim 2.5 \log$ units for ASHE and ASDE, respectively (99.9\%).

\subsection{ASHE and ASDE Treatments Caused Extracellular and Intracellular Damage to Test Bacterial Strains}

3.3.1. SEM. When treated with ASHE and ASHE at $1 \mathrm{x}, 2 \mathrm{x}$, and $4 \mathrm{x}$ MICs for $4 \mathrm{~h}$, several morphological changes in the cells were observed (Figure 4). Untreated and DMSO treated samples of MSSA (Figures 4(a) and 4(b)) and MRSA (Figures 4(i) and 4(j)) appeared in normal round shape with smooth cell surfaces. Acinetobacter baumannii (Figures 4(q) and 4(r)) cells appeared as smooth coccobacilli and S. maltophilia (Figures 4(y) and 4(z)) appeared normal rod shaped with clear smooth cell surfaces. Rough and damaged surfaces with bumps and ruptured lines on cell surfaces were observed in ASHE and ASDE treated samples of MSSA, MRSA, and A. baumannii (Figures 4(c)-4(f), 4(g), 4(k)-4(p), 4(t), and $4(\mathrm{u}))$. At higher concentrations of ASHE and ASDE (2x and $4 \mathrm{x}$ ), burst cells of $S$. maltophilia were observed (Figures 4(ab) and 4(ac)). Lysed cells and cell debris of MSSA, MRSA, A. baumannii, and S. maltophilia were also observed (Figures 4(ab), 4(ac), 4(v)-4(x), and 4(ad)-4(af)).

3.3.2. TEM. When treated with ASHE and ASHE at $1 \mathrm{x}$ and $2 \mathrm{x}$ MICs for $4 \mathrm{~h}$, the intracellular damage and cell leakages were evident in extract treated samples (Figure 5). Nontreated and DMSO treated (control) samples of MSSA (Figures 5(a) and 5(b)) and MRSA (Figures 5(g) and 5(h)), A. baumannii (Figures 5(m) and 5(n)), and S. maltophilia (Figures $5(\mathrm{~s})$ and $5(\mathrm{t}))$ showed intact cell shapes with homogenous cell wall and regular cell membranes. Disruption of cell membrane was observed in samples treated with $1 \mathrm{x}$ MIC (Figures 5(c)-5(f), 5(k), 5(l), 5(o)-5(q), 5(p), and 5(q)) and at increasing concentrations of ASHE/ASDE (2x MIC), ghost cells (Figures 5(i), 5(j), 5(l), 5(o), and 5(q)) and leakage of membrane components (Figures 5(o), 5(q), and 5(u)-5(x)) were observed.

3.4. The Effect of ASHE and ASDE on S. aureus, A. baumannii, and S. maltophilia Biofilms. Challenging preformed biofilms of MSSA, MRSA, A. baumannii, and S. maltophilia with ASHE and ASDE resulted in significant reduction in biofilm viability. As shown in Figure 6, ASHE and ASDE disrupted/removed adherent biofilms at 1x, 2x, and 4x MICs in a concentration dependent manner. ASHE at $1 \times$ MIC showed slight reduction in the biofilm viability of MSSA (64 $\mu \mathrm{g} \mathrm{mL}^{-1}$ ) (Figure 6(a)), MRSA $\left(32 \mu \mathrm{g} \mathrm{mL}^{-1}\right.$ ) (Figure 6(b)), A. baumannii $\left(32 \mu \mathrm{g} \mathrm{mL}{ }^{-1}\right.$ ) (Figure 6(c)), and S. maltophilia $\left(64 \mu \mathrm{g} \mathrm{mL}^{-1}\right.$ ) (Figure 6(d)). Meanwhile, ASDE at $1 \times$ MIC showed a slight reduction in the biofilm viability of MSSA (16 $\left.\mu \mathrm{g} \mathrm{mL}^{-1}\right)$, MRSA (64 $\left.\mu \mathrm{g} \mathrm{mL}^{-1}\right)$, A. baumannii $\left(32 \mu \mathrm{g} \mathrm{mL}^{-1}\right)$, and S. maltophilia $\left(64 \mu \mathrm{g} \mathrm{mL} \mathrm{m}^{-1}\right)$. At $4 \mathrm{x}$ MICs, MSSA and S. maltophilia biofilms were highly susceptible to ASHE and ASDE (Figures 6(a) and 6(d)).

3.5. In Situ Analysis of Biofilm Formation. Figure 7 displays a series of CLSM images of the biofilms, before and after ASHE and ASDE treatments at varying concentrations. The controls (biofilms and DMSO treated) images on the $1^{\text {st }}$ and $2^{\text {nd }}$ columns as shown by the typical two-dimensional biofilm architectures of MSSA (Figures 7(a) and 7(b)), MRSA (Figures 7(i) and 7(j)), A. baumannii (Figures 7(q) and $7(\mathrm{r})$ ), and S. maltophilia (Figures $7(\mathrm{y})$ and $7(\mathrm{z})$ ) displayed well-developed biofilms (Figure 7), while bacterial samples treated with ASHE and ASDE at $1 \mathrm{x}$ MICs showed significant reduction in biofilms (Figures 7(a), 7(f), 7(k), 7(n), 7(s), 7(v), 


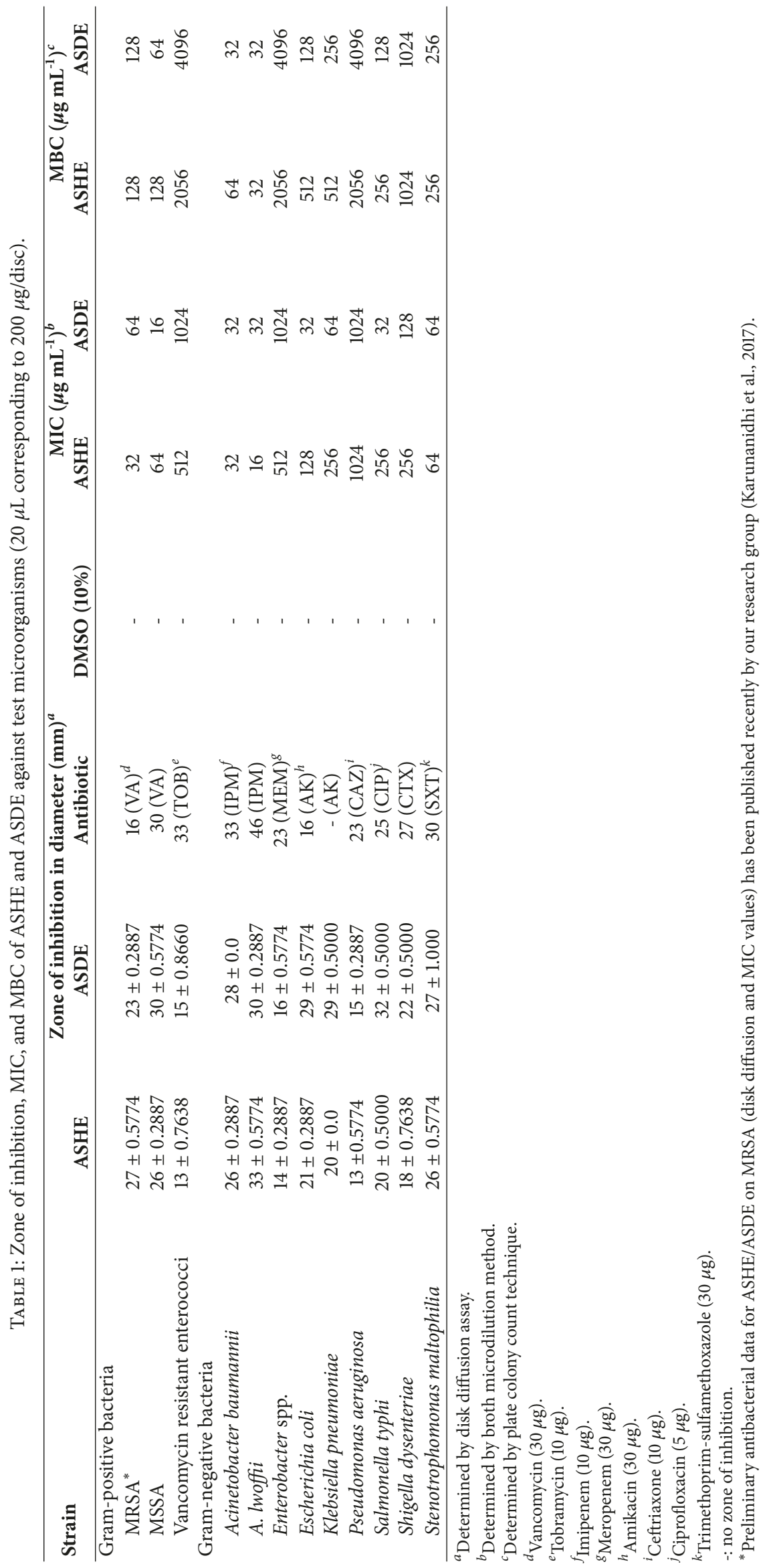




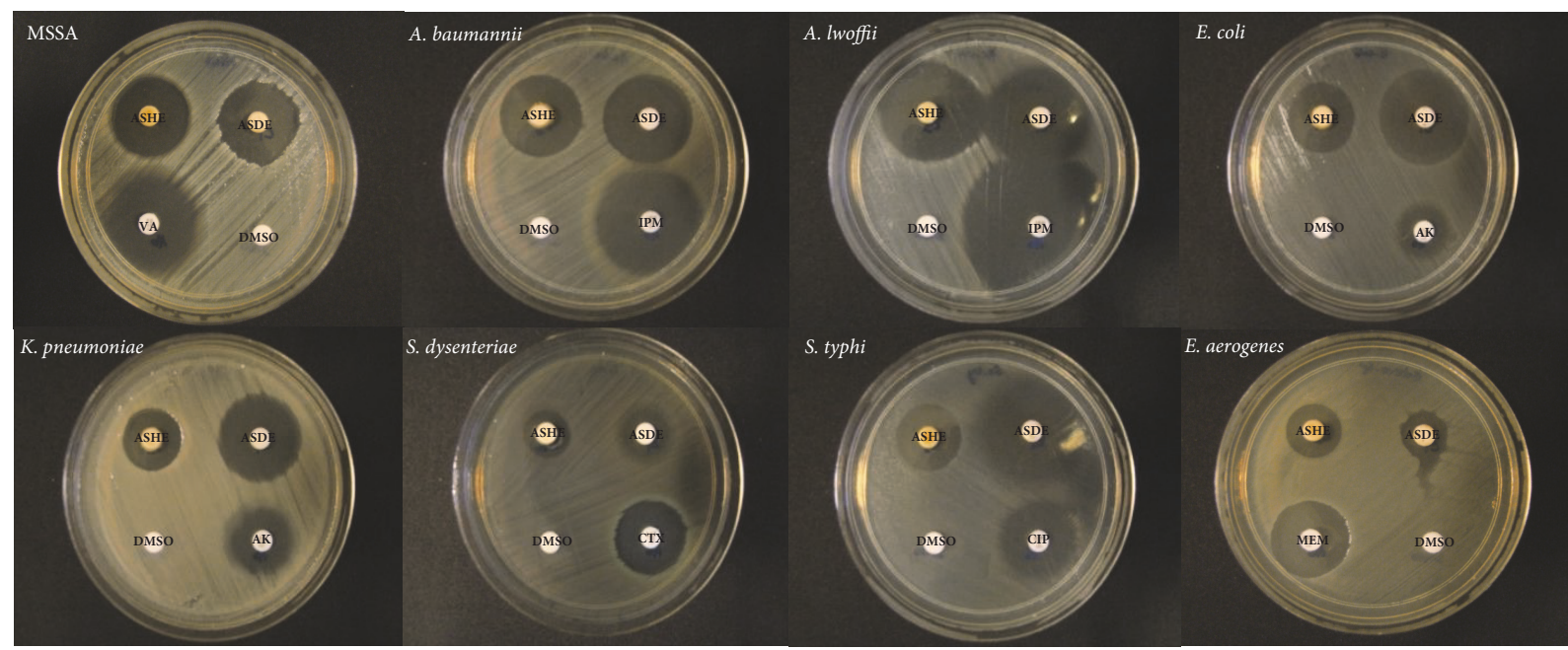

FIGURE 1: Effect of ASHE $\left(200 \mu \mathrm{g} \mathrm{disc}^{-1}\right)$ and $\operatorname{ASDE}\left(200 \mu \mathrm{g}\right.$ disc $\left.^{-1}\right)$ applied to a blank filter paper disk on MHA plate inoculated with the test microorganisms. ASHE: A. stipitatum hexane extract; ASDE: A. stipitatum dichloromethane extract; VA: vancomycin (30 $\mu \mathrm{g})$; IPM: imipenem $(10 \mu \mathrm{g})$; AK: amikacin $(30 \mu \mathrm{g})$; CTX: ceftriaxone (10 $\mu \mathrm{g})$; CIP: ciprofloxacin (5 $\mu \mathrm{g})$; MEM: meropenem (10 $\mu \mathrm{g})$; DMSO: dimethyl sulfoxide $(10 \%)$.

$7(\mathrm{aa})$, and $7(\mathrm{ad}))$. Meanwhile, CLSM images viewed at 20x, 60x, and 100x (in control biofilms and DMSO) unveiled the adhering ability of strong biofilm producers like MRSA, $A$. baumannii, and S. maltophilia, which led to the development of dense biofilm formation on glass coverslips. Meanwhile samples treated at increasing concentrations of ASHE and ASDE (2x and 4x MICs) clearly exhibited the antibiofilm potential of ASHE and ASDE by disintegrating the biofilm architecture of $S$. aureus (Figures $7(\mathrm{~d}), 7(\mathrm{e}), 7(\mathrm{~g})$, and $7(\mathrm{~h})$ ), MRSA (Figures $7(\mathrm{l}), 7(\mathrm{~m}), 7(\mathrm{o})$, and $7(\mathrm{p}))$, A. baumannii (Figures $7(\mathrm{t}), 7(\mathrm{u}), 7(\mathrm{w})$, and $7(\mathrm{x})$ ), and S. maltophilia (Figures $7(\mathrm{ab}), 7(\mathrm{ac}), 7(\mathrm{ae})$, and $7(\mathrm{af}))$.

\section{Discussion}

This is the first report on two different extracts from the same botanical product with antibacterial activity against MSSA, MRSA, A. baumannii, and S. maltophilia biofilms and their planktonic counterparts. The presence of allicin in the bulbs of $A$. hirtifolium (also known as Persian shallot locally) has been demonstrated by thin layer chromatography (TLC) methods [20]. In our earlier investigation on the in vivo antibacterial and burn wound healing properties of A. stipitatum, both ASHE and ASDE were subjected to gas chromatography mass spectrometer (GC-MS) analysis [24]. Although the antibacterial compound allicin was not detected in the GC-MS analysis, several sulfur-containing compounds including $S$-methyl methanethiosulfonate, 2,4,5-trithiahexane, 2,4-dithiapentane, 2-pyridinethione, and methane (chloromethylthio) (methylthio) were detected in our recently published work [24]. Similar components were also reported in the hydromethanolic extract of $A$. hirtifolium as detected by GMCS [21]. In their analysis, the hydromethanolic extract of $A$. hirtifolium was reported to be effective against MSSA, MRSA, S. typhi, E. coli, and K. pneumoniae with zone sizes ranging from 10 to $18 \mathrm{~mm}$ at 1.2 $\mathrm{mg} /$ disc concentration [21]. However, the use of nonpolar extracts (ASHE and ASDE) in this study resulted in a slightly higher activity. The strong antibacterial activity of ASHE and ASHE against the test pathogens can be attributed to the presence of volatile sulfur-containing compounds in the extracts as compared to the amount detected in the hydromethanolic extract reported elsewhere [21]. Another significance of the present study is the relatively equal potency exerted by ASHE and ASDE especially in killing gram-negative pathogens. Preliminary antibacterial data on the anti-MRSA activity of ASHE and ASDE based on disk diffusion and MIC experiments has been published recently by our research group [24]. Therefore, the disk diffusion plate picture for MRSA was not shown in Figure 1. However, the time-kill assay, electron microscopy images, and antibiofilm data of MRSA were included in the present study. Ismail et al. [21] reported that the inhibition zones exerted by hydromethanolic extract at $60 \mathrm{mg} \mathrm{mL}^{-1}$ towards grampositive and gram-negative pathogens were in the ranges of $11-15 \mathrm{~mm}$ and $10-14 \mathrm{~mm}$ diameter, respectively. However, in the present study, ASHE at $10 \mathrm{mg} \mathrm{mL}^{-1}$ exerted zone sizes of 13-27 mm towards gram-positive bacteria and 13-33 mm towards gram-negative bacteria. Meanwhile, ASDE exerted zone sizes of $15-30 \mathrm{~mm}$ towards gram-positive bacteria and 15-32 $\mathrm{mm}$ towards gram-negative bacteria. Another significance of the present study is the use of emerging antibiotic resistant pathogens such as A. baumannii, $S$. maltophilia, and VRE which were highly susceptible to ASHE and ASDE. Based on the above data, it is evident that both ASHE and ASDE were equally potent in inhibiting both gram-positive and emerging gram-negative bacterial pathogens even at very low concentrations.

According to a previous study, the MIC values of hydromethanolic extract ranged from 1.88 to $7.50 \mathrm{mg} \mathrm{mL}^{-1}$ 


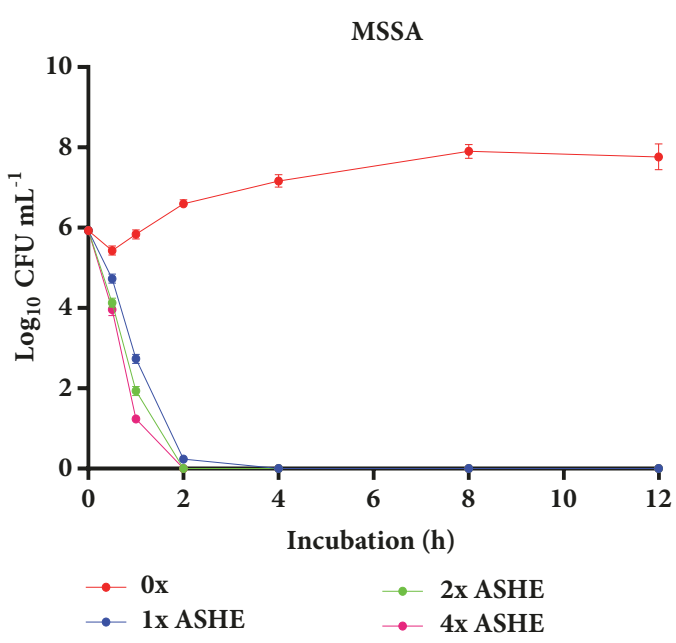

(a)

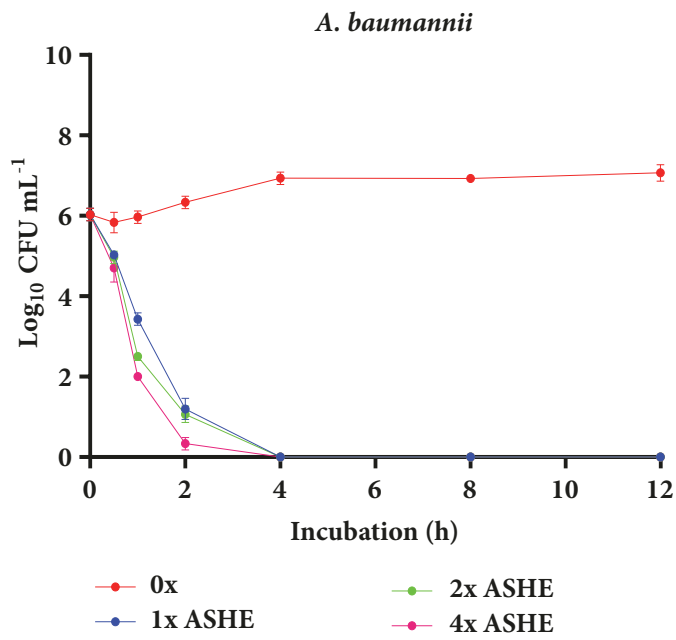

(c)

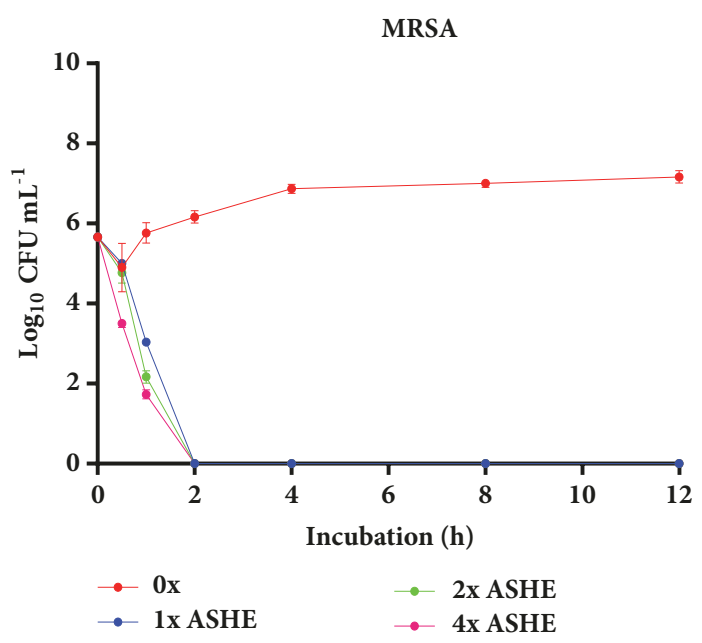

(b)

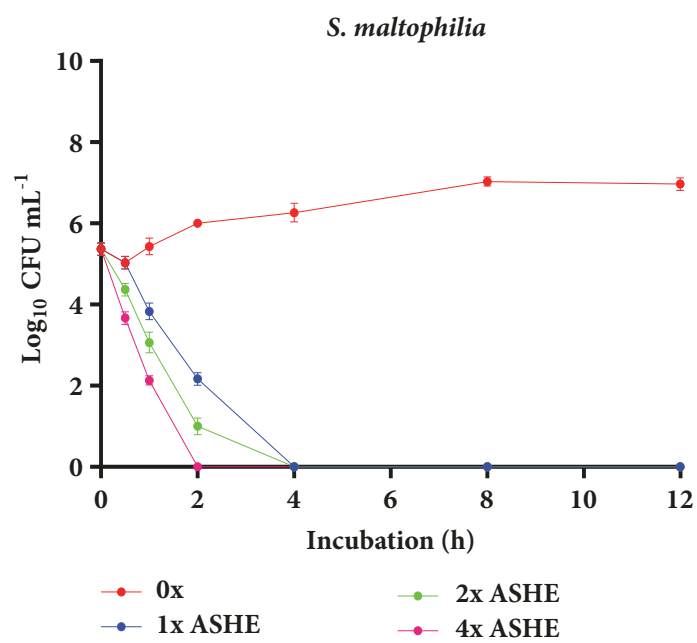

(d)

FIgURE 2: Effect of ASHE on the viability of (a) MSSA, (b) MRSA, (c) A. baumannii, and (d) S. maltophilia in liquid medium (time-kill curve) exposed with ASHE at concentrations of $1 \mathrm{x}, 2 \mathrm{x}$, and $4 \mathrm{x}$ MIC with control (0x MIC). MIC: minimum inhibitory concentration; CFU: colony-forming units.

for gram-positive and gram-negative pathogens [21]. In the present study, ASHE and ASDE were strongly antibacterial and the MICs were as low as $32 \mu \mathrm{g} \mathrm{mL}^{-1}$ against epidemiologically important superbug like MRSA. The MICs of ASHE and ASDE were in the range of $16-1024 \mu \mathrm{gL}^{-1}$, while the MBCs ranged between 32 and $4096 \mu \mathrm{g} \mathrm{mL} L^{-1}$. Such low levels of MICs for a natural product extract against emerging antibiotic resistant pathogens are noteworthy and advantageous compared with compounds of synthetic origin.

Few reports are available on the nontoxic antibacterial and cytoprotective effects of chloroformic and hydromethanolic extracts of $A$. hirtifolium $[19,21]$. Moreover, in our earlier investigation on the anti-MRSA and burn wound healing properties of A. stipitatum, both extracts (ASHE and ASDE) were proven to be noncytotoxic and safe to Vero cells at $<400 \mu \mathrm{g} \mathrm{mL} L^{-1}$ [24]. In terms of antibacterial activity, the MICs of ASHE and ASDE against all grampositive (except VRE) and gram-negative bacteria (except
Enterobacter spp. and $P$. aeruginosa) were in the ranges of $16-256 \mu \mathrm{g} \mathrm{mL}^{-1}$ and $16-128 \mu \mathrm{g} \mathrm{mL}^{-1}$, respectively. The above MIC values were comparatively lesser than the $\mathrm{CC}_{50}$ concentrations on Vero cells $\left(383.4 \mu \mathrm{g} \mathrm{mL}^{-1} ; 390.4 \mu \mathrm{g} \mathrm{mL}^{-1}\right)$ which is therapeutically acceptable for a nontoxic edible natural extract. The cytotoxicity results as reported in our previous study [24] and the strong antibacterial activity of ASHE and ASDE at low concentrations clearly underline that nonpolar extracts of A. stipitatum can be successfully used as promising alternatives in managing gram-positive and gramnegative pathogens.

Several studies have reported on the preliminary antibacterial activity of $A$. hirtifolium [21, 31, 32]; however, investigation on the bactericidal effect of Persian shallot extract has never been reported elsewhere. Determination of the minimum time required by ASHE/ASDE in killing a pathogen will help in investigating the mechanism of action which involves studies like transcriptomic, gene expression analysis, 


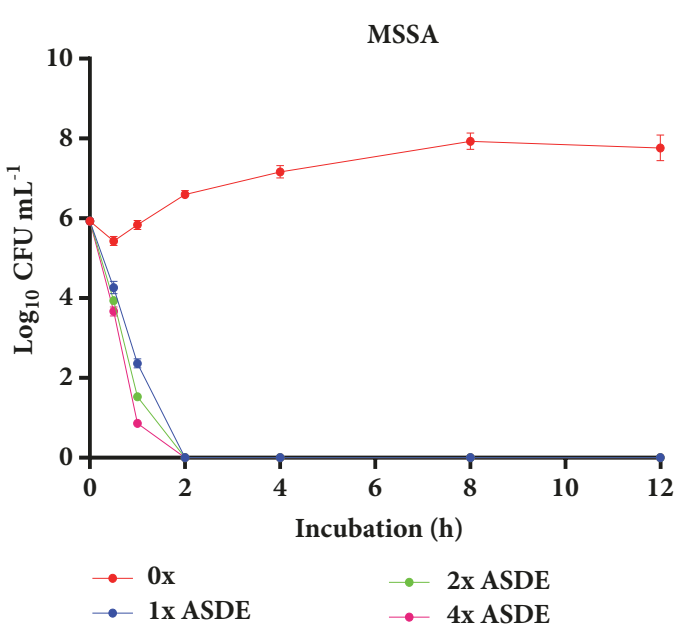

(a)

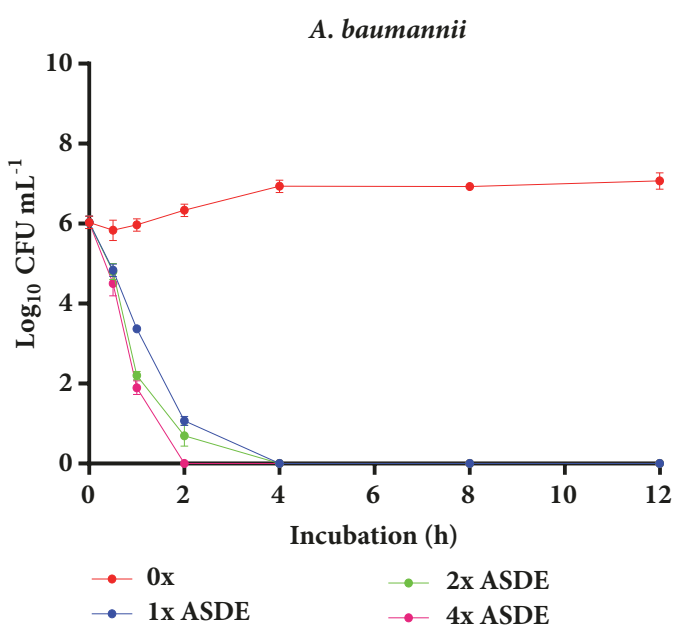

(c)

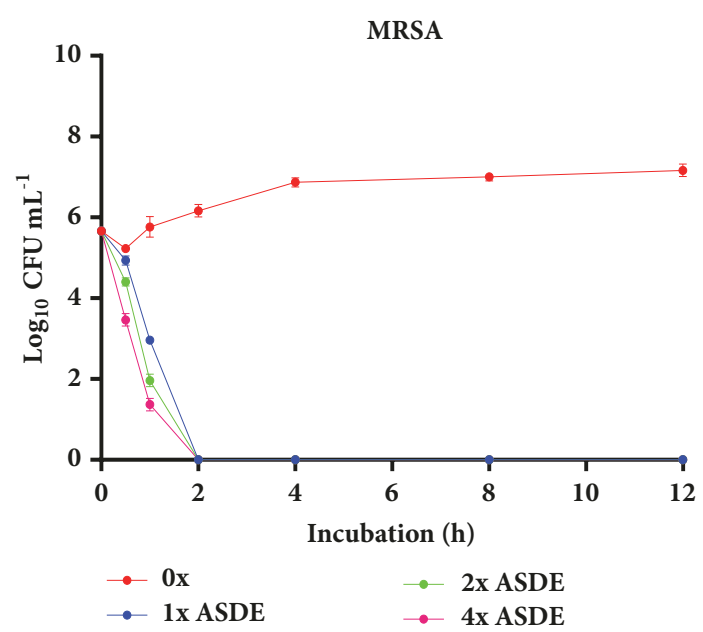

(b)

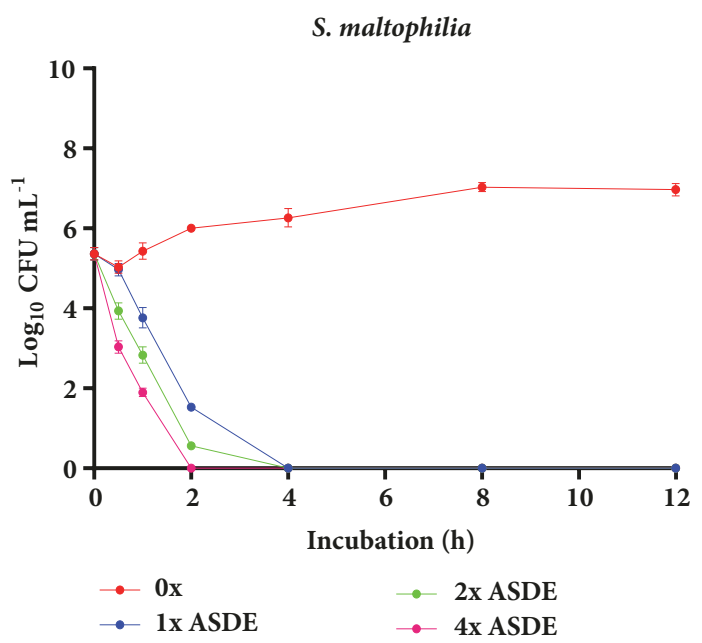

(d)

FIGURE 3: Effect of ASDE on the viability of (a) MSSA, (b) MRSA, (c) A. baumannii, and (d) S. maltophilia in liquid medium (time-kill curve) exposed with ASDE at concentrations of $1 \mathrm{x}, 2 \mathrm{x}$, and $4 \mathrm{x}$ MIC with control (0x MIC). MIC: minimum inhibitory concentration; CFU: colony-forming units.

and enzyme assays. Based on the data on time-kill assay, cell counts were found to be either too few to count (TFTC) or zero in MHA plates with bacterial inoculum plated after 4 $\mathrm{h}$ postinoculation. The colony counts of test bacteria treated with ASHE and ASDE at $2 \mathrm{x}$ and $4 \mathrm{x}$ MICs varied, but interestingly the killing time was the same for all the concentrations tested. The killing efficiency of both ASHE and ASDE towards S. aureus, MRSA, A. baumannii, and S. maltophilia was comparatively similar with slight variations in colony counts which could be due to the solvent's (dichloromethane) nature as a chlorinated solvent. No evidence of recurrence or growth was observed among the 4 pathogens tested which imply that the extracts are strongly bactericidal by completely killing the test pathogens in 2-4 hpi with an $\sim 2$ to 2.5 log reduction in the inoculum. The above findings are partly in agreement with Nidadavolu et al. [33] who reported $\sim 7 \log$ reduction in A. baumannii, $\sim 8 \log$ reduction in S. aureus, and $\sim 2 \log$ reduction in Enterococcus faecalis biofilms upon treatment with garlic oil. In addition, MDR strains of A. baumannii have been reported to be highly susceptible to chloroform extract of garlic [34]. Increasing concentrations of the extracts $(2 \mathrm{x}$ and $4 \mathrm{x}$ MICs) did not show significant changes in the killing time, but the colony counts varied slightly which implies that the killing efficacy of ASHE and ASDE was concentration dependent.

Biofilm-related casualties due to $S$. aureus, MRSA, A. baumannii, and $S$. maltophilia are becoming more persistent in susceptible hospitalized patients with indwelling catheters or artificial grafts [35-37]. In the present study, S. aureus and $S$. maltophilia biofilms were more susceptible to ASHE and ASDE especially at $1 \mathrm{x}$ MIC levels $(p<0.001, p<0.001)$ as compared to MRSA and A. baumannii $(p<0.001, p<0.001)$, but statistically significant reduction in biofilm reduction was evident. One limitation of the present study is that the antibiofilm activities of ASHE and ASDE were tested only on mature biofilms (24-hour-old biofilm) and not on early 

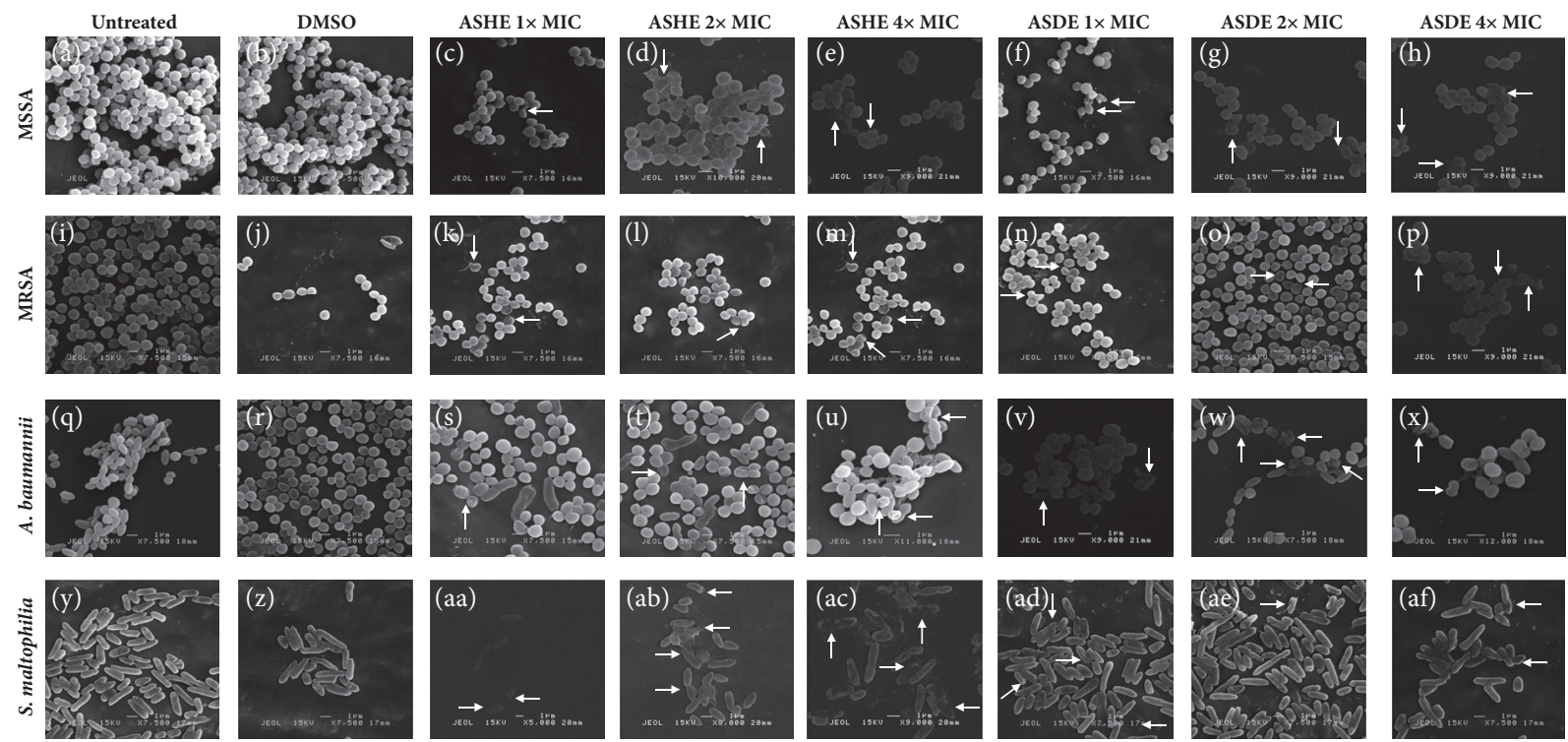

FIGURE 4: Scanning electron micrographs of test microorganisms treated with ASHE and ASDE. Panels (a-h) MSSA; (i-p) MRSA; (q-x) A. baumannii; (y-af) S. maltophilia. SEM magnification, $\times 5000$ to $\times 12000$. Bar indicates $1 \mu \mathrm{m}$.
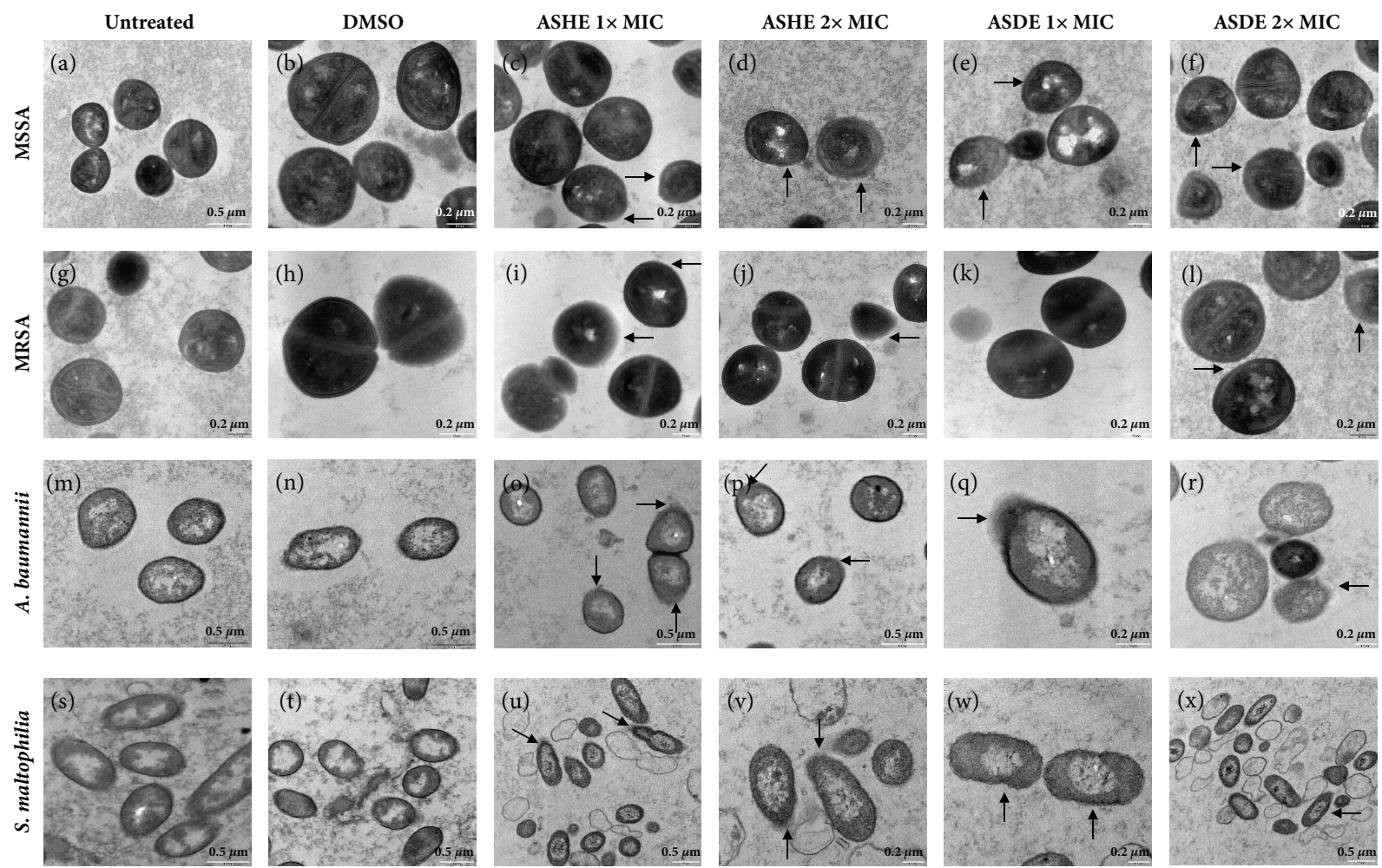

Figure 5: Transmission electron micrographs of test microorganisms treated with ASHE and ASDE. Panel (a-f) MSSA, (g-l) MRSA, (m-r) A. baumannii, and (s-x) S. maltophilia. SEM magnification, $\times 5000$ to $\times 12000$. Bar indicates $1 \mu \mathrm{m}$.

biofilms (6-hour-old partial biofilm). In fact, mature biofilms are dense, thicker, and increasingly resistant to antibiotics as compared to early biofilms at $6 \mathrm{~h}$. Both extracts were equally potential in penetrating deeper layers of the mature biofilms and effective in killing bacterial biofilms. Based on these results, it is evident that in addition to the broad-spectrum antibacterial activity towards planktonic bacteria, ASHE and ASDE possess antibiofilm activity on gram-positive and gram-negative biofilms. In an earlier investigation, Lee et al. [38] reported that garlic extract increases the biofilm formation by the oral biofilm colonizer Streptococcus mutans to orthodontic wire. However, the findings of the present 


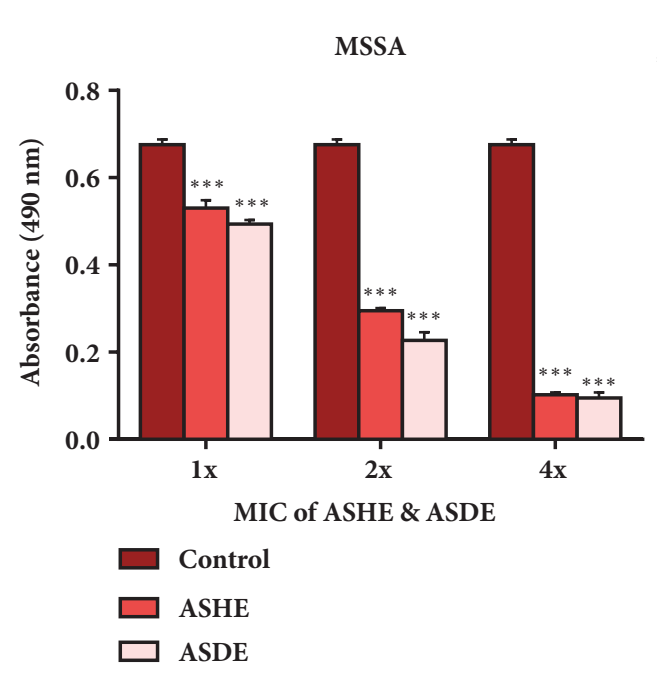

(a)

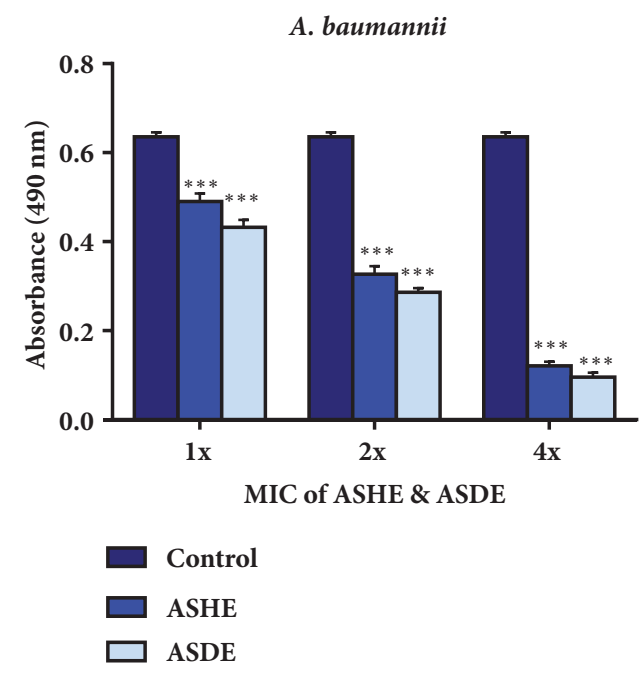

(c)

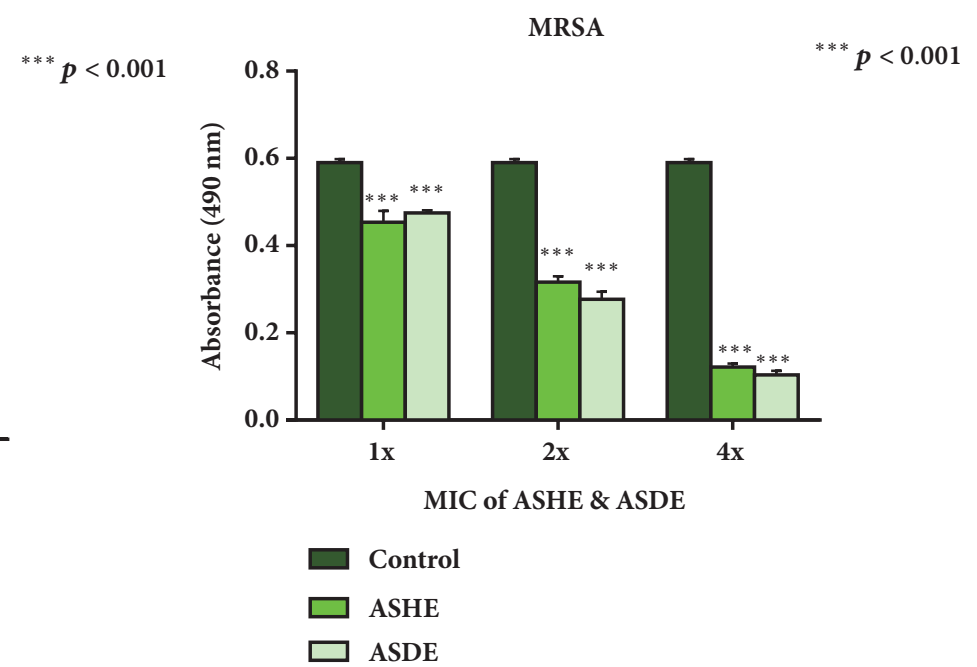

(b)

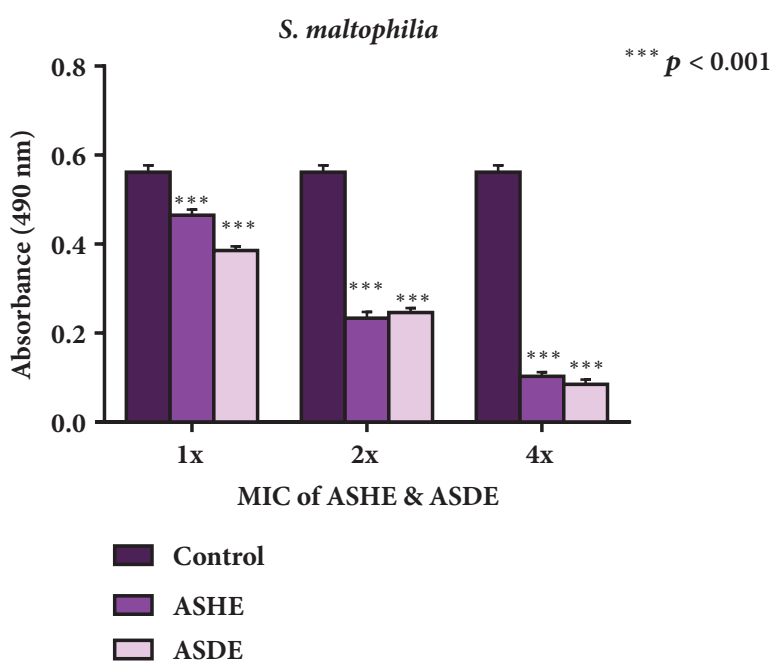

(d)

FIGURE 6: Effect of ASHE and ASDE on the viability of (a) S. aureus, (b) MRSA, (c) A. baumannii, and (d) S. maltophilia biofilms at concentrations of $1 \mathrm{x}, 2 \mathrm{x}$, and $4 \mathrm{x}$ MICs with control (0x MIC). Comparison of absorbance between control and treated samples at $490 \mathrm{~nm}$ by XTT assay. ${ }^{* * *} p<0.001$; MIC: minimal inhibitory concentration. Values are expressed as mean \pm SD.

study are contradictory, where A. stipitatum being a member of the Allium family disrupted matured biofilms of the MDR pathogens. According to Lee et al. [38], garlic oil (GarO) was shown to prevent biofilm development in burn wound pathogens such as $S$. aureus and A. baumannii [33]. These results were in agreement with the present study results implying that ASHE and ASDE could be possibly used as a prophylactic therapy to prevent biofilm associated infections upon further investigations.

Bacterial cell wall and cell membrane play a vital role in the survival, biofilm formation, and antibiotic resistance of a pathogen. Hence, a slight damage induced by a natural/synthetic antimicrobial compound could result in metabolic dysfunction/cell death. SEM and TEM experiments are highly essential techniques [27] in order to reveal any possible cell surface effects and/or intracellular alterations induced by ASHE/ASDE. It is evident from the
SEM experiments that both gram-positive and gram-negative organisms tested showed signs of deep craters, burst, rough and damaged surfaces with depression, rupture lines, and cell debris. TEM experiments also showed clear disruption of bacterial membrane and leakage, which emphasize the bactericidal potentials of $A$. stipitatum.

Effective disruption and reduction of microcolonies were evidenced by CLSM images (Figure 7). The exact molecular mechanism underlying the growth and biofilm inhibition by ASHE and ASDE in MDR pathogens is not known; however, a recent investigation on the antibacterial effects of garlic (Allium sativum) concentrate and garlic-derived organosulfur compounds targets the cell membrane of Campylobacter jejuni [39]. Diallyl thiosulfinate (allicin) an active ingredient in garlic is known to inhibit RNA synthesis in S. typhimurium [40]. The use of crude plant extracts like ASHE/ASDE may be a valuable tool for future developments, also keeping in 

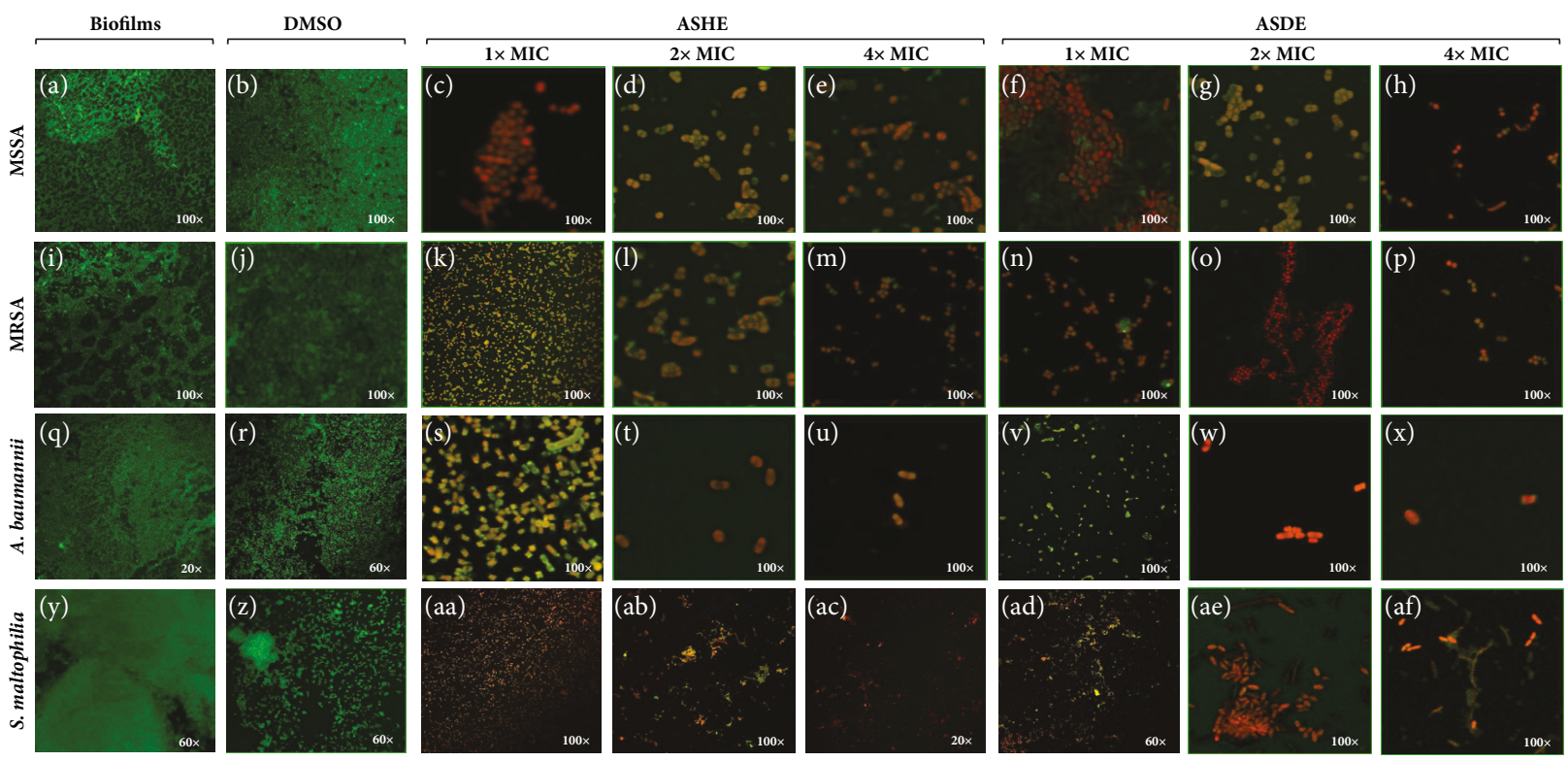

FIGURE 7: Representative confocal images of mature biofilms and ASHE and ASDE treated biofilms. Panels (c-h) represent ASHE and ASDE treated groups of MSSA. Panels $(\mathbf{k}-\mathbf{p})$ represent ASHE and ASDE treated groups of MRSA. Panels $(\mathbf{s}-\mathbf{x})$ represent ASHE and ASDE treated groups of A. baumannii. Panels (aa-af) represent ASHE and ASDE treated groups of S. maltophilia. Micrographs of fluorescent biofilms were obtained by confocal microscopy.

mind how economical it can be to obtain such preparations. However, further investigations must be carried out to define which of the many compounds from the multitarget crude mixtures is directed against which enzyme/protein.

\section{Conclusion}

Allium stipitatum is a source for bioactive compounds such as antioxidants, anticancer, and antimicrobial agents and has been shown here to have bioactive potential against pathogenic biofilms. The data presented here provides sufficient in vitro antibacterial activity and further extends the potential of $A$. stipitatum as an antibiofilm agent in addition to explaining the traditional use of Persian shallot as an antimicrobial agent. Hence, the combinatorial use of A. stipitatum extracts along with antibiotics could help to eradicate MDR pathogens and biofilm associated infections in hospital settings. Studies on the isolation of the bioactive compound and its mechanism of action are currently under investigation in our laboratory.

\section{Abbreviations}

ASHE: Allium stipitatum hexane extract

ASDE: Allium stipitatum dichloromethane extract

MSSA: Methicillin-sensitive Staphylococcus aureus

MRSA: Methicillin-resistant Staphylococcus aureus

MIC: Minimum inhibitory concentration

MBC: Minimum bactericidal concentrationNomenclature
XTT: 2,3-Bis(2-methoxy-4-nitro-5-sulfophenyl)$2 \mathrm{H}$-tetrazolium-5-carboxanilide

CLSM: Confocal laser scanning microscopy

MDR: Multidrug resistant

hpi: Hours postinoculation

ATCC: American Type Culture Collection

TSA: Tryptic soy agar

TSB: Tryptic soy broth

NA: Nutrient agar

LB: Luria-Bertani

BHI: Brain heart infusion

MHA: Mueller-Hinton agar

MHB: Mueller-Hinton broth

PBS: $\quad$ Phosphate-buffered saline

CLSI: Clinical and Laboratory Standards Institute

CFU: Colony-forming units

SEM: Scanning electron microscopy

TEM: Transmission electron microscopy

CPD: Critical point drying

TLC: Thin layer chromatography

GC-MS: Gas chromatography mass spectrometer

VRE: Vancomycin resistance enterococci

TFTC: Too few to count

RNA: Ribonucleic acid.

\section{Data Availability}

The data used to support the findings of this study are available from the corresponding author upon request.

\section{Conflicts of Interest}

The authors declare that they have no conflicts of interest. 


\section{Acknowledgments}

The authors acknowledge the Department of Medical Microbiology and Parasitology, Faculty of Medicine and Health Sciences, UPM, for providing research facilities. Arunkumar Karunanidhi is thankful to the staff at Microscopy Unit, Institute of Biosciences, UPM, for their technical assistance in sample preparation. This research was supported by UPM through the Research University Grant Scheme (RUGS, Grant no. 04-02-1756 RU) funded by the Ministry of Higher Education (MOHE), Putrajaya, Malaysia.

\section{References}

[1] N. Høiby, T. Bjarnsholt, M. Givskov, S. Molin, and O. Ciofu, "Antibiotic resistance of bacterial biofilms," International Journal of Antimicrobial Agents, vol. 35, no. 4, pp. 322-332, 2010.

[2] P. S. Stewart and J. W. Costerton, "Antibiotic resistance of bacteria in biofilms," The Lancet, vol. 358, no. 9276, pp. 135-138, 2001.

[3] J. W. Costerton, P. S. Stewart, and E. P. Greenberg, "Bacterial biofilms: a common cause of persistent infections," Science, vol. 284, no. 5418, pp. 1318-1322, 1999.

[4] T. J. Hannan, M. Totsika, K. J. Mansfield, K. H. Moore, M. A. Schembri, and S. J. Hultgren, "Host-pathogen checkpoints and population bottlenecks in persistent and intracellular uropathogenic Escherichia coli bladder infection," FEMS Microbiology Reviews, vol. 36, no. 3, pp. 616-648, 2012.

[5] A. S. Lynch and G. T. Robertson, "Bacterial and fungal biofilm infections," Annual Review of Medicine, vol. 59, pp. 415-428, 2008.

[6] T. F. Mah and G. A. O’Toole, "Mechanisms of biofilm resistance to antimicrobial agents," Trends in Microbiology, vol. 9, no. 1, pp. 34-39, 2001.

[7] P. Gilbert, D. Allison, and A. McBain, "Biofilms in vitro and in vivo: do singular mechanisms imply cross-resistance?" Journal of Applied Microbiology, vol. 92, no. s1, pp. 98S-110S, 2002.

[8] H. Wu, C. Moser, H.-Z. Wang, N. Høiby, and Z.-J. Song, "Strategies for combating bacterial biofilm infections," International Journal of Oral Science, vol. 7, pp. 1-7, 2015.

[9] C. De La Fuente-Núñez, M. H. Cardoso, E. De Souza Cândido, O. L. Franco, and R. E. W. Hancock, "Synthetic antibiofilm peptides," Biochimica et Biophysica Acta (BBA) - Biomembranes, vol. 1858, no. 5, pp. 1061-1069, 2016.

[10] P. Y. Chung and R. Khanum, "Antimicrobial peptides as potential anti-biofilm agents against multidrug-resistant bacteria," Journal of Microbiology, Immunology and Infection, vol. 50, no. 4, pp. 405-410, 2017.

[11] P. Y. Chung and Y. S. Toh, "Anti-biofilm agents: recent breakthrough against multi-drug resistant Staphylococcus aureus," Pathogens and Disease, vol. 70, no. 3, pp. 231-239, 2014.

[12] N. Rabin, Y. Zheng, C. Opoku-Temeng, Y. Du, E. Bonsu, and H. O. Sintim, "Agents that inhibit bacterial biofilm formation," Future Medicinal Chemistry, vol. 7, no. 5, pp. 647-671, 2015.

[13] E. Buommino, M. Scognamiglio, G. Donnarumma, A. Fiorentino, and B. D'Abrosca, "Recent advances in natural product-based anti-biofilm approaches to control infections," Mini-Reviews in Medicinal Chemistry, vol. 14, no. 14, pp. 1169-1182, 2015.

[14] A. Asili, J. Behravan, M. Reza Naghavi, and J. Asili, "Genetic diversity of persian shallot (Allium hirtifolium) ecotypes based on morphological traits, allicin content and RAPD markers," Open Access Journal of Medicinal and Aromatic Plants, vol. 1, no. 1, pp. 1-6, 2010.

[15] R. Ebrahimi, Z. Zamani, and A. Kashi, "Genetic diversity evaluation of wild Persian shallot (Allium hirtifolium Boiss.) using morphological and RAPD markers," Scientia Horticulturae, vol. 119, no. 4, pp. 345-351, 2009.

[16] V. E. Rubatzky and M. Yamaguchi, World Vegetables, Principles, Production and Nutritive Values, Chapman \& Hall/International Thompson Publishing, New York, NY, USA, 1997.

[17] V. Mozaffarian, Dictionary of Iranian Plants Names (LatinEnglish-Persian), Farhange Moaser, Tehran, Iran, 1996.

[18] H. G. Azadi, B. Fathi, and H. K. Mehrjerdi, "Macroscopic evaluation of wound healing activity of the Persian shallot, Allium hirtifolium in rat," Iran. J. Vet. Sci. Technol, vol. 3, no. 1, pp. 31-38, 2011.

[19] H. G. Azadi, G. H. Riazi, S. M. Ghaffari, S. Ahmadian, and T. J. Khalife, "Effects of Allium hirtifolium (Iranian shallot) and its allicin on microtubule and cancer cell lines," African Journal of Biotechnology, vol. 8, no. 19, pp. 5030-5037, 2009.

[20] H. Ghodrati Azadi, S. M. Ghaffari, G. H. Riazi, S. Ahmadian, and F. Vahedi, "Antiproliferative activity of chloroformic extract of Persian Shallot, Allium hirtifolium, on tumor cell lines," Cytotechnology, vol. 56, no. 3, pp. 179-185, 2008.

[21] S. Ismail, F. A. Jalilian, A. H. Talebpour et al., "Chemical Composition and Antibacterial and Cytotoxic Activities of Allium hirtifolium Boiss," BioMed Research International, vol. 2013, Article ID 696835, pp. 1-8, 2013.

[22] A. Jafarian, A. Ghannadi, and A. Elyasi, "The effects of Allium hirtifolium Boiss. on cell-mediated immune response in mice," Iran. J. Pharm. Res, vol. 2, pp. 51-55, 2003.

[23] M. Taran, M. Rezaeian, and M. Izaddoost, "Invitro antitrichomonas activity of Allium hirtifolium (persian shallot) in comparison with metronidazole," Iranian Journal of Public Health, vol. 35, no. 1, pp. 92-94, 2006.

[24] A. Karunanidhi, E. Ghaznavi-Rad, J. J. Nathan, Y. Abba, A. Van Belkum, and V. Neela, "Allium stipitatum extract exhibits in vivo antibacterial activity against methicillin-resistant staphylococcus aureus and accelerates burn wound healing in a fullthickness murine burn model," Evidence-Based Complementary and Alternative Medicine, vol. 2017, 2017.

[25] Arunkumar Karunanidhi, Renjan Thomas, Alex van Belkum, and Vasanthakumari Neela, "In Vitro Antibacterial and Antibiofilm Activities of Chlorogenic Acid against Clinical Isolates of Stenotrophomonas maltophilia including the Trimethoprim/Sulfamethoxazole Resistant Strain," BioMed Research International, vol. 2013, Article ID 392058, pp. 1-7, 2013.

[26] CLSI, "Performance Standards for Antimicrobial Susceptibility Testing," Twenty-Fifth Informational Supplement. CLSI Document M100-S25, 2015.

[27] M. Hartmann, M. Berditsch, J. Hawecker, M. F. Ardakani, D. Gerthsen, and A. S. Ulrich, "Damage of the bacterial cell envelope by antimicrobial peptides gramicidin S and PGLa as revealed by transmission and scanning electron microscopy," Antimicrobial Agents and Chemotherapy, vol. 54, no. 8, pp. 31323142, 2010.

[28] E. Peeters, H. J. Nelis, and T. Coenye, "Comparison of multiple methods for quantification of microbial biofilms grown in microtiter plates," Journal of Microbiological Methods, vol. 72, no. 2, pp. 157-165, 2008. 
[29] M. A. R. Amalaradjou, A. Narayanan, S. A. Baskaran, and K. Venkitanarayanan, "Antibiofilm effect of trans-cinnamaldehyde on uropathogenic Escherichia coli," The Journal of Urology, vol. 184, no. 1, pp. 358-363, 2010.

[30] X. Chen, H. Hirt, Y. Li, S.-U. Gorr, and C. Aparicio, "Antimicrobial GL13K peptide coatings killed and ruptured the wall of streptococcus gordonii and prevented formation and growth of biofilms," PLoS ONE, vol. 9, no. 11, Article ID el11579, 2014.

[31] M. Amin, E. A. Montazeri, M. A. Mashhadizadeh, and A. F. Sheikh, "Characterization of shallot, an antimicrobial extract of Allium ascalonicum," PAKISTAN JOURNAL OF MEDICAL SCIENCES, vol. 25, no. 6, pp. 948-952, 2009.

[32] F. Ashrafi, A. Akhavan Sepahi, and A. Kazemzadeh, "Effect of aqueous extract of shallot (Allium ascalonicum) on inhibition of growth of Pseudomonas aeruginosa," Iran. J. Pharm. Res, vol. 3, no. 2, pp. 71-71, 2004.

[33] P. Nidadavolu, W. Amor, P. L. Tran, J. Dertien, J. A. ColmerHamood, and A. N. Hamood, "Garlic ointment inhibits biofilm formation by bacterial pathogens from burn wounds," Journal of Medical Microbiology, vol. 61, no. 5, pp. 662-671, 2012.

[34] N. H. Jazani, S. Shahabi, A. A. Ali, S. Zarrin, and N. A. Daie, "In vitro antibacterial activity of garlic against isolates of Acinetobacter sp," Journal of Biological Sciences, vol. 7, no. 5, pp. 819-822, 2007.

[35] R. M. Donlan, "Biofilms and device-associated infections," Emerging Infectious Diseases, vol. 7, no. 2, pp. 277-281, 2001.

[36] R. M. Donlan and J. W. Costerton, "Biofilms: survival mechanisms of clinically relevant microorganisms," Clinical Microbiology Reviews, vol. 15, no. 2, pp. 167-193, 2002.

[37] N. K. Pour, D. H. Dusane, P. K. Dhakephalkar, F. R. Zamin, S. S. Zinjarde, and B. A. Chopade, "Biofilm formation by Acinetobacter baumannii strains isolated from urinary tract infection and urinary catheters," FEMS Immunology \& Medical Microbiology, vol. 62, no. 3, pp. 328-338, 2011.

[38] H.-J. Lee, H.-S. Park, K.-H. Kim, T.-Y. Kwon, and S.-H. Hong, "Effect of garlic on bacterial biofilm formation on orthodontic wire," The Angle Orthodontist, vol. 81, no. 5, pp. 895-900, 2011.

[39] X. Lu, B. A. Rasco, J. M. F. Jabal, D. Eric Aston, M. Lin, and M. E. Konkel, "Investigating antibacterial effects of garlic (Allium sativum) concentrate and garlic-derived organosulfur compounds on Campylobacter jejuni by using fourier transform infrared spectroscopy, Raman spectroscopy, and electron microscopy," Applied and Environmental Microbiology, vol. 77, no. 15, pp. 5257-5269, 2011.

[40] R. S. Feldberg, S. C. Chang, and A. N. Kotik, "In vitro mechanism of inhibition of bacterial cell growth by allicin," Antimicrobial Agents and Chemotherapy, vol. 32, no. 12, pp. 1763-1768, 1988. 


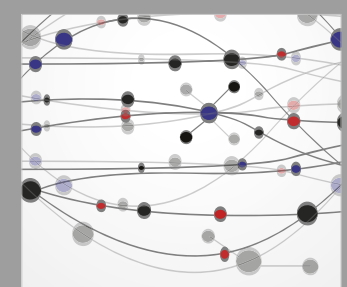

The Scientific World Journal
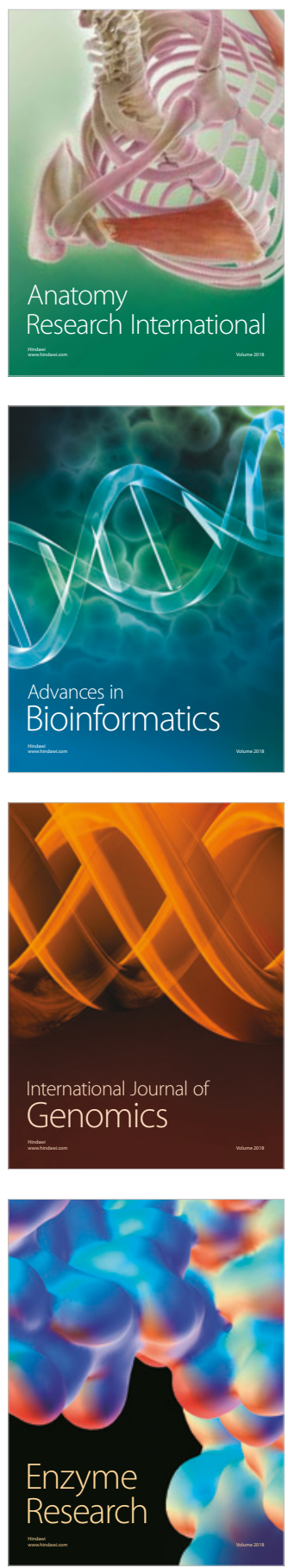
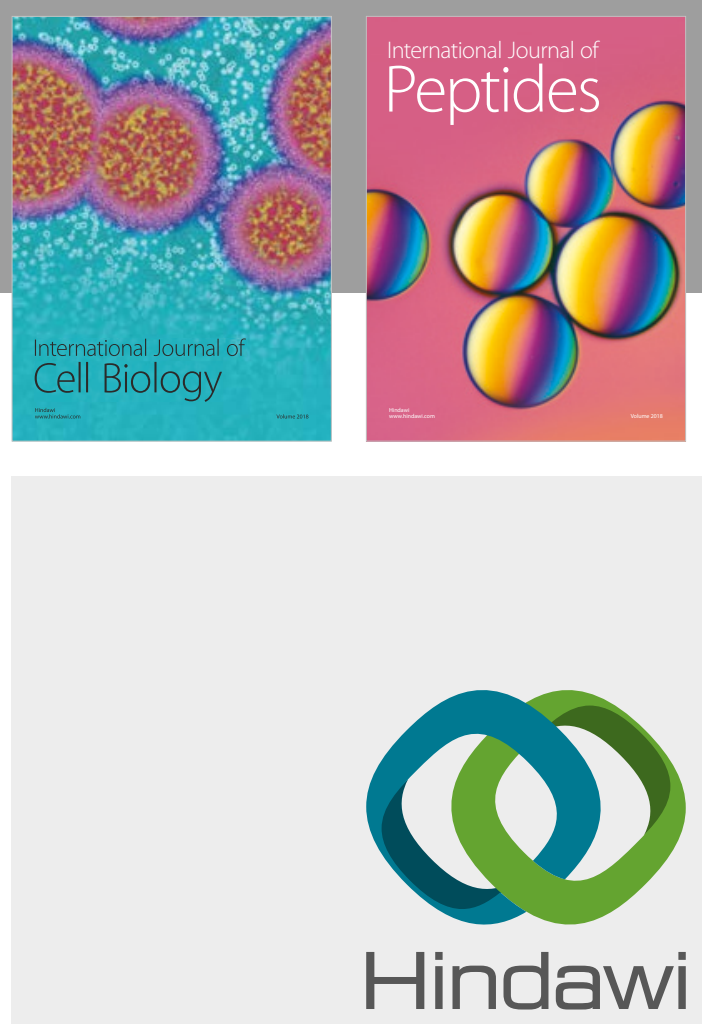

Submit your manuscripts at

www.hindawi.com
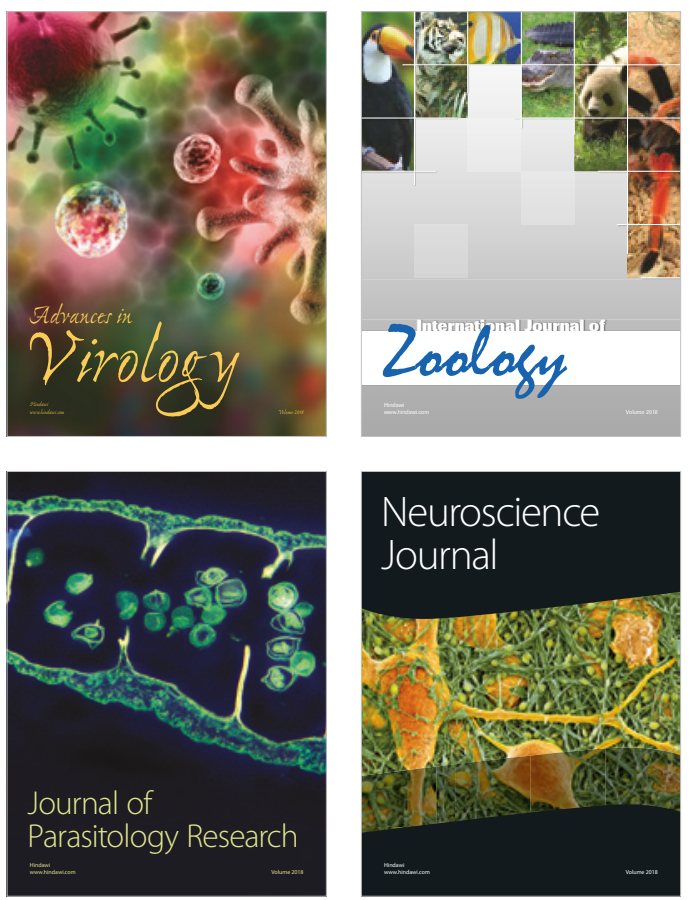
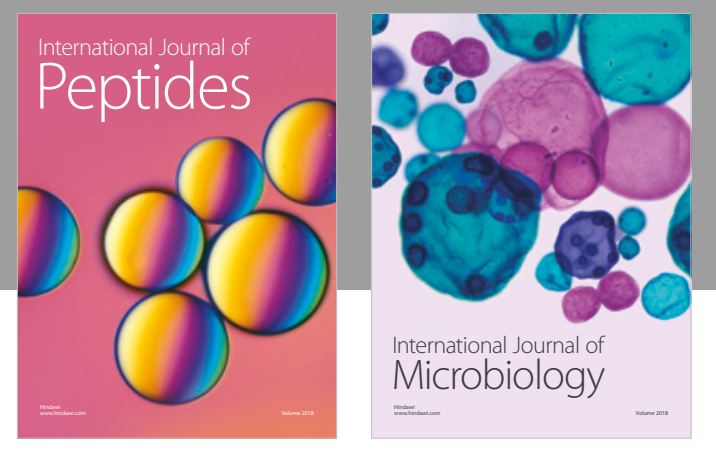

nternational Journal of Microbiology
Journal of
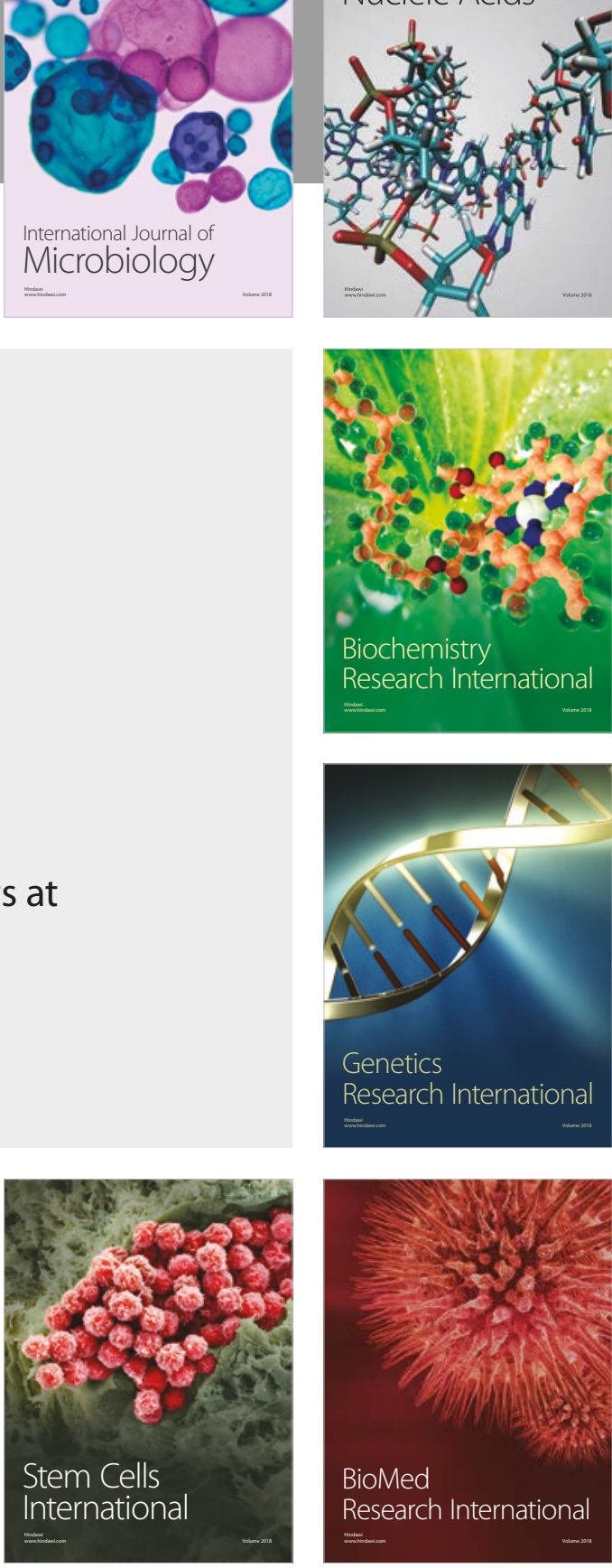
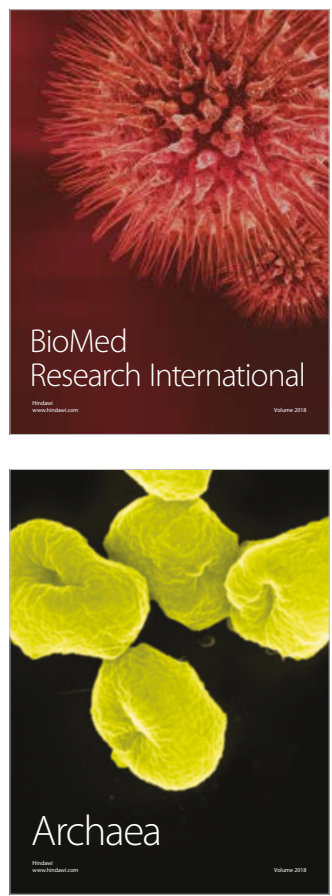